\title{
A Case of Atrophia Maculosa Varioliformis Cutis
}

\author{
Dong Hyun Kim, M.D., Seung Min Lee, M.D. ${ }^{1}$, Tae Yoon Kim, M.D., Moon Soo Yoon, M.D. \\ Department of Dermatology, College of Medicine, Pochon CHA University, Seongnam, \\ ${ }^{1}$ Department of Dermatology, National Police Hospital, Seoul, Korea
}

\begin{abstract}
Atrophia maculosa varioliformis cutis is a rare disease that was first described by Heidingsfeld in 1918. It is characterized by an idiopathic, non-inflammatory macular atrophy that typically occurs on the face in young individuals. Despite its association with some diseases, the etiopathogenesis of this entity remains unknown. After consideration of the differential diagnosis criteria for idiopathic atrophic conditions, we report a case for a 40 -year-old Korean male whose past medical history was suggestive of atrophia maculosa varioliformis cutis.
\end{abstract}

(Ann Dermatol (Seoul) 20(4) 247 249, 2008)

Key Words: Atrophia maculosa varioliformis cutis, Face, Scar

\section{INTRODUCTION}

Atrophia maculosa varioliformis cutis (AMVC) is a rare disease whose characteristics were first noted by Heidingsfeld ${ }^{1}$ in 1918 to describe numerous, spontaneously formed scars on the cheeks of a 20-year-old man. Some of those lesions resembled the scars of smallpox. Characteristically, macular atrophy appears spontaneously on the face in the absence of prior trauma or inflammation. The course is usually chronic and slowly progressive. Although most cases are sporadic, familial occurrence has recently been reported. Its etiopathogenesis remains unknown. We report a case that occurred in a 40-year-old Korean male whose past medical history was suggestive of atrophia maculosa varioliformis cutis.

\section{CASE REPORT}

A 40-year-old Korean man presented with several

\section{Received August 27, 2007}

Accepted for publication June 9, 2008

Reprint request to: Moon Soo Yoon, M.D., Department of Dermatology, Bundang CHA Medical Center, 351, Yatap-dong, Bundang-gu, Seongnam 463-712, Korea. Tel: 82-31-780-5242, Fax:82-31-780-5247, E-mail: msch11@ chamc.co.kr asymptomatic, depressed scars on the face. His skin lesions had appeared since the age of 7 and had worsened during the 2 months before he visited our clinic. The patient denied any prior trauma to or inflammation of his face. On physical examination, there were two well-demarcated skin-colored atrophic scars that measured $3 \times 2 \mathrm{~mm}$ and several pitted scars located on the right cheek (Fig. 1). The atrophic, chicken pox-like scars were not compressible upon palpation. The remainder of the skin examination was unremarkable except for oily skin. He denied any history of conditions that could account for the cutaneous scars, including acne

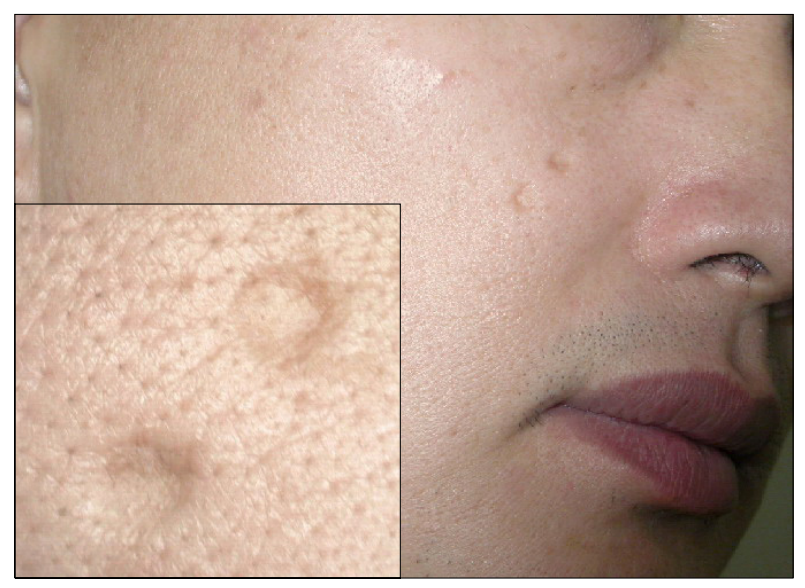

Fig. 1. Two well-demarcated skin-colored atrophic scars measuring $3 \times 2 \mathrm{~mm}$ located on the right cheek. 


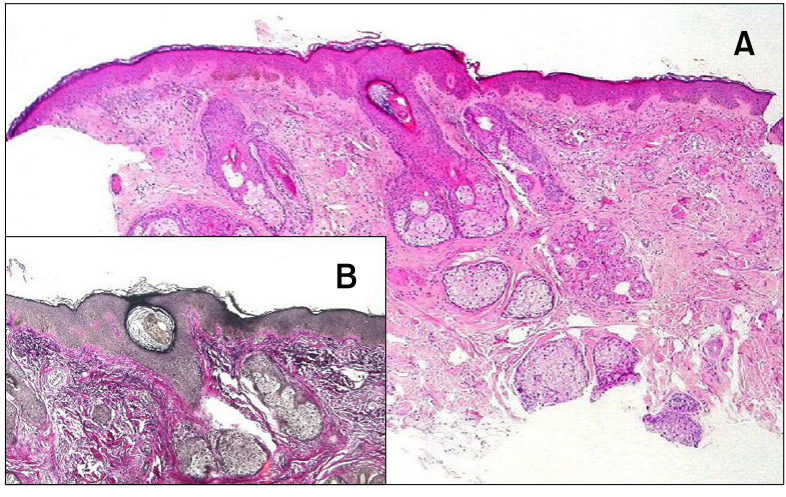

Fig. 2. (A) Slightly atrophied epidermis and solar elastosis in the upper dermis $(H \& E, \times 40)$. (B) Note the elastotic material in the superficial and mid-dermis (inset) (Verhoeff van Gieson, ×100).

vulgaris, varicella, milia, epidermal cyst or psychiatric illness. Past medical history revealed diabetes mellitus and hyperlipidemia. Familial occurrence of similar skin lesions was unremarkable. A $3 \mathrm{~mm}$ skin punch biopsy specimen showed a slightly atrophied epidermis, solar elastosis in the upper dermis and elastotic material in the superficial and mid-dermis by Verhoeff van Gieson stain (Fig. 2).

On the basis of the clinical features, histological findings and no prior history of facial lesions, we made a diagnosis of atrophia maculosa varioliformis cutis. We could narrow the width of the scars by punch biopsy and the scar depth became shallower with 3 courses of $50 \%$ TCA dot peeling. At 1-year follow-up, the cosmetic outcome was excellent.

\section{DISCUSSION}

Atrophia maculosa varioliformis cutis (AMVC) is a rare condition that is characterized by subtle, slightly depressed lesions on the temples and cheeks at a young age. In the English literature, only 23 cases have been reported since the first description of this condition ${ }^{1}$. Despite the small number of cases, there are several features that make AMVC a distinct entity.

AMVC occurs primarily on the face, and most frequently involves the bilateral buccal regions. The scars or depressions have been variously described as linear, round, irregular round or varioliform ${ }^{2-5}$.
They have well-demarcated or step-like margins and no pigmentary changes when compared to the surrounding $\mathrm{skin}^{4}$. Their sizes range from 0.2 to 2.0 $\mathrm{cm}$ in length, $0.2 \sim 0.5 \mathrm{~cm}$ in width and have a subjective depth of $0.2 \mathrm{~cm}$. Patients have denied any history of scarring that was secondary to acne or varicella infection, or the presence of any prior skin lesions. However, some had noticed a slight erythema that faded upon scar formation ${ }^{6}$. The lesions of AMVC are usually asymptomatic; our patient's lesions were not pruritic. Very mild acne lesions have been observed in some patients with AMVC $^{7}$. Although slightly oily skin was observed in our case, the patient denied any prior acne lesions on his face.

The etiology of AMVC remains unknown. In the literature, associated diseases include extrahepatic biliary atresia ${ }^{8}$, pachydermodactyly ${ }^{9}$ and keratosis pilaris atrophicans ${ }^{10}$. However, there were no associated diseases for our case. Recently, some cases have revealed a familial occurrence, which suggests that AMVC may be an inherited disease, , $10-13^{2}$.

The histological findings are variable, including epidermal thinning, a mild perivascular lymphocytic infiltrate, decreased or fragmented elastic fibers and/ or normal or increased collagen in the superficial or mid-dermis ${ }^{3-5}$. Kolenik et $\mathrm{al}^{4}$ postulated a slight decrease in elastic fibers beneath the epidermal depression, but several reports have shown a normal amount of elastic fiber in the dermis ${ }^{3,5,7}$. Dall'Oglio et $\mathrm{al}^{11}$ reported the presence of scarce, small, fragmented elastic fibers and compact collagen bundles associated with hypertrophic fibroblasts in the dermis on ultrastructural studies. Our case showed no fragmented elastic fibers in the papillary dermis, except for a finding of solar elastosis.

Differential diagnoses include scars related to acne, varicella, atrophoderma vermiculata or dermatitis artefacta. Atrophoderma vermiculata is characterized by a 'honeycomb'-type atrophy on the cheeks, which presumably is a late reaction to inflammation around horny follicular plugs. We found no evidence that the scars for our case were preceded by the aforementioned inflammatory conditions.

No specific treatment options have been proposed for the management of AMVC. Filler injections, dermabrasion or laser resurfacing may be helpful.

In conclusion, AMVC should be considered in the differential diagnosis of idiopathic macular 
atrophy when it is supported by the appropriate patient history and clinical findings.

\section{REFERENCES}

1. Heidingsfeld ML. Atrophia maculosa varioliformis cutis. J Cutan Dis 1918;36:285-288.

2. McCorriston LR, Roys HC. Atrophia maculosa varioliformis cutis. AMA Arch Derm Syphilol 1951;64:59-61.

3. Marks VJ, Miller OF. Atrophia maculosa varioliformis cutis. Br J Dermatol 1986;115:105-109.

4. Kolenik SA, Perez MI, Davidson DM, Morganroth GS, Kohn SR, Bolognia JL. Atrophia maculosa varioliformis cutis. Report of two cases and review of the literature. J Am Acad Dermatol 1994;30: 837-840.

5. Nakayama H, Mihara M. Atrophia maculosa varioliformis cutis. Acta Derm Venereol 1995;75: 252.

6. Kuflik JH, Schwartz RA, Becker KA, Lambert WC. Atrophia maculosa varioliformis cutis. Int J Dermatol 2005;44:864-866.

7. Criado PR, Pegas JR, Tebecherani A, Souza AC,
Sueto M, Pires MC. Atrophia maculosa varioliformis cutis: a case with extrafacial involvement and familial facial lesions. J Eur Acad Dermatol Venereol 2005;19:764-766.

8. Venencie PY, Foldes C, Cuny M, Samuel D, Bismuth H. Atrophia maculosa varioliformis cutis with extrahepatic biliary atresia. J Am Acad Dermatol 1989;21:309.

9. Callot V, Wechsler J, Hovnanian A, Revuz J. Pachydermodactyly and atrophia maculosa varioliformis cutis. Dermatology 1995;190:56-58.

10. Gordon PM, Doherty VR. Familial atrophia maculosa varioliformis cutis. Br J Dermatol 1996; 134:982-983.

11. Dall'Oglio F, Nasca MR, Taparelli F, Bacchelli B, Micali G. Familial atrophia maculosa varioliformis cutis: an ultrastructural study. Pediatr Dermatol 2001;18:230-233.

12. Kalayciyan A, Kotogyan A, Demirkesen C, Tuzun Y. Familial atrophia maculosa varioliformis cutis. Int J Dermatol 2003;42:530-532.

13. Qu T, Wang B, Fang K. Familial atrophia maculosa varioliformis cutis: case report and pedigree analysis. Br J Dermatol 2005;153:821-824. 